УДК 327(73)

ББК 63.3(7Coe)

\title{
Венгерский мятеж и Суэцкий кризис 1956 г.: пределы и возможности американской дипломатии
}

\author{
В.П. Румяниев
}

Национальный исследовательский Томский государственный университет (Томск, Россия)

\section{Hungarian Revolution and Suez Crisis of 1956: Limits and Possibilities of American Diplomacy}

\author{
V.P. Rumyantsev
}

National Research Tomsk State University (Tomsk, Russia)

\begin{abstract}
В истории международных отношений периода «холодной войны» особенно выделяется 1956 г. В этот год параллельно, практически день в день, развивались два острых международных кризиса, один в Восточной Европе, другой - на Ближнем Востоке. У венгерского мятежа и Суэцкого кризиса были независимые друг от друга причины возникновения. Общим для них было то, что в обоих случаях свою роль сыграла вовлеченность в них Советского Союза и Соединенных Штатов Америки. Степень этой вовлеченности различалась. Для американской политики времен президента Д. Эйзенхауэра характерным были заявления, что успеху американской дипломатии в Венгрии, нацеленной на «отбрасывание коммунизма», якобы, помешала англо-франко-израильская агрессия против Египта, предпринятая ближайшими союзниками США. В статье доказывается, что администрация 34-го президента Соединенных Штатов придерживалась прагматического подхода, не собираясь оказывать помощи венгерским мятежникам, а ограничиваясь пропагандистскими мерами. А гнев лидеров республиканцев в Вашингтоне вызывали возможные последствия тройственной агрессии в отношении кампании по перевыборам Д. Эйзенхауэра в должности президента, но отнюдь не мнимые расчеты на победу мятежников в Венгрии.
\end{abstract}

Ключевые слова: венгерский мятеж, Суэцкий кризис, Соединенные Штаты, Д. Эйзенхауэр.

DOI 10.14258/izvasu(2019)5-11

Политика Соединенных Штатов Америки в странах Восточной Европы является темой актуальной не только с политической, но и с научной точки зрения. Среди сюжетов, посвященных степени участия Вашингтона в тех или иных событиях социально-политической жизни стран этого региона, особое место
The year of 1956 stands out in the history of international relations during the Cold War. It was that year, when in parallel, two acute international crises developed almost simultaneously, one crisis developed in Eastern Europe and another one developed in the Middle East. The Hungarian revolution and the Suez crisis were independent of each other. But they had in common one fact. In both cases the involvement of the Soviet Union and the United States of America played a role. The extent of the involvement varied. For the American policy of the period of President Eisenhower, there were statements that the success of American diplomacy in Hungary aimed at "rollback of communism" was allegedly prevented by the AngloFrench-Israeli aggression against Egypt undertaken by the closest allies of the United States. This article proves that the administration of the $34^{\text {th }}$ President of the United States followed a pragmatic approach not intending to provide assistance to Hungarian rebels and limited to propaganda measures. And the anger of the Republican leaders in Washington was caused by the possible consequences of the tripartite aggression against the re-election campaign of Dwight Eisenhower as a president, but by no means imaginary calculations on the victory of the revolution in Hungary.

Key words: Hungarian Revolution, Suez Crisis, United States, Dwight Eisenhower.

занимает венгерский мятеж 1956 г. События середины 1950-х гг. однозначно трактуются венгерскими авторами К. Бекешем, Л. Борхи, М. Мольнаром, Я. Радванем как «революция» [1-4]. Мнение, что это не просто мятеж, а настоящая революция, почти всецело разделяется в зарубежной исто- 
бежной историографии [5-8]. В отечественной историографии закрепилась трактовка событий 1956 г. как «мятежа» или «восстания». В издании сборника документов, подготовленном под эгидой Совместной комиссии историков России и Венгрии, составители предпочли использовать термин «кризис» [9]. Одним из наиболее распространенных сюжетов истории событий в Венгрии является их международный аспект. Активную работу в этом направлении ведет американская исследовательница Дж. Грэнвилл. Ее работы посвящены позиции Югославии, Румынии, ГДР, Австрии в связи с событиями в Будапеште осенью 1956 г. [10, р. 493-517; 11, p. 62-90; 12, p. 477-502; 13 , р. 88-121]. Особое место в историографии венгерского мятежа, по понятным причинам, занимает политика Советского Союза, которую профессор МГИМО Т.В. Зонова справедливо предлагает рассматривать в широком контексте «холодной войны» $[14$, с. 198-211]. Безусловно, американо-советское противостояние оказало влияние на события 1956 г. в Венгрии. Одной из первых работ, посвященных этому сюжету, стало исследование аналитика Центрального разведывательного управления (ЦРУ) США Б. Макколи, который охарактеризовал политику Соединенных Штатов в отношении восстания в Будапеште как «активное невмешательство» $[15$, p. 777-800]. Он же одним из первых предложил рассматривать эту политику в глобальном международном плане, учитывая возникший в том же 1956 г. Суэцкий кризис на Ближнем Востоке. Со времени публикации Б. Макколи прошло уже около 40 лет. Были рассекречены архивы, появились новые материалы, доступные для исследователей. Интересная попытка выявления взаимосвязи событий в Венгрии и Суэцкого кризиса была предпринята британским исследователем П. Бойлом. Признавая правильность поставленного им вопроса («в какой степени кризис на Ближнем Востоке повлиял на изменение советской политики в Венгрии?» [16, р. 556]), следует рассмотреть и другой вопрос. А именно - какую роль сыграл венгерский мятеж в политике США в отношении Суэцкого кризиса? Попытка ответить на этот вопрос является целью написания данной статьи.

К обострению ситуации вокруг Суэцкого канала привел ряд факторов, в числе которых было складывание нового соотношения военных сил на Ближнем Востоке в результате закупок Египтом осенью 1955 г. вооружения у стран Варшавского договора, политическое и экономическое давление США и Великобритании на Египет, осуществлявшееся в целях оказания воздействия на внешнеполитический курс египетского президента Г. А. Насера. 26 июля 1956 г. правительство Египта объявило о национализации компании Суэцкого канала. Ведущие страны НАТО предприняли попытки вернуть морской канал, проходящий по египетской территории, под свой контроль. 1956 г. был годом выборов президента США, и американское правительство, учитывая задачу переизбрания Д. Эйзенхауэра на второй срок президентства, сочло необходимым сделать акцент на дипломатическом урегулировании вопроса о статусе Суэцкого канала [17, с. 88]. 29 октября 1956 г., за неделю до президентских выборов в США, Израиль начал военные действия против Египта. Через несколько дней к нему присоединились Великобритания и Франция. Данная ситуация ставила администрацию Д. Эйзенхауэра в сложное положение, поскольку в тройственной агрессии против Египта участвовали ближайшие союзники Соединенных Штатов.

В процессе принятия внешнеполитических решений во время Суэцкого кризиса администрация Д. Эйзенхауэра неизменно учитывала интересы глобальной внешней политики США. Внимание американской дипломатии осенью 1956 г. вызывали не только события на Ближнем Востоке, но и процессы, происходящие в странах Восточной Европы. Это внимание было вызвано и хронологическим совпадением Суэцкого кризиса и мятежа в Венгрии, а также стремлением правительства Соединенных Штатов координировать свою региональную политику с учетом изменения международной обстановки в мире.

Политика США в отношении восточноевропейского региона во многом была обусловлена осуществленным еще во время Второй мировой войны разделом сфер влияния между участниками антигитлеровской коалиции. Страны Восточной Европы, по договоренности между Москвой, Вашингтоном и Лондоном, относились к сфере интересов Советского Союза. В целом, разграничение сфер влияния соответствовало задачам внешней политики США. Незначителен был и экономический интерес Соединенных Штатов к этому региону. Тем не менее США не оставляли надежд со временем вовлечь восточноевропейские страны в орбиту влияния Вашингтона.

Одной из основных задач послевоенной американской внешней политики было противодействие распространению влияния СССР. В отношении Центральной и Восточной Европы во время первого срока президентства Д. Эйзенхауэра одним из главных лозунгов было «отбрасывание коммунизма». Критикуя предшествующую администрацию Г. Трумэна за якобы пассивную политику «сдерживания» СССР, представители республиканской партии настаивали на проведении более решительной, наступательной восточноевропейской политики. Одним из центральных тезисов избирательной кампании 1952 г. влиятельный республиканец Дж.Ф. Даллес предлагал сделать тему «освобождения» Восточной Европы от влияния Советского Союза. В мае 1952 г. в журнале «Лайф» была опу- 
бликована статья Даллеса «Политика отваги», в которой он настаивал, чтобы США публично заявили о своем желании и готовности добиваться «освобождения» народов этой части Европы. В общих чертах в данной статье была показана та политика, которой республиканцы собираются придерживаться в отношении Центральной и Восточной Европы [18]. В действительности, как понимал ставший государственным секретарем Дж. Ф. Даллес и как он доказывал Совету Национальной Безопасности в 1953 г., стратегия «освобождения» и «отбрасывания коммунизма» должна быть рассчитана «на очень отдаленную перспективу» и подчинена долгосрочным планам ослабления советского влияния во всем мире [19, p. 711, 834].

В ходе всестороннего анализа американской внешней политики, проведенного Советом Национальной Безопасности (СНБ) США осенью 1953 г., был выработан программный документ «Основы политики национальной безопасности», одобренный Эйзенхауэром 30 октября 1953 г., в котором утверждалось, что «отделение какого-либо европейского сателлита от советского блока вряд ли осуществимо» $[19$, р. 580, 777-778]. При этом специалистами госдепартамента и ЦРУ признавалось, что в ближайшие несколько лет ниспровержение контроля СССР над странами Центральной и Восточной Европы путем восстаний в этих государствах маловероятно.

Возможности осуществления восточноевропейской политики США были ограничены меньшим, в сравнении с суммами, выделявшимися для других регионов, объемом финансовых фондов Вашингтона, предназначенных для проведения политики в отношении Центральной и Восточной Европы. В связи с этим американское правительство вынуждено было сфокусировать свое внимание в основном на пропагандистской кампании. Особое внимание уделялось финансированию деятельности специальных радиостанций типа «Голос Америки», «Свободная Европа», в передачах которых нередко содержалась, по существу, программа действий для людей, не согласных с порядками, существующими в странах народной демократии. Зачастую эти радиостанции прямо призывали народы Центральной и Восточной Европы к восстанию, давая советы по тактике вооруженного сопротивления [20, p. 824].

Кроме того, ЦРУ активно вело работу с прозападными кругами этих стран, зачастую выходя за рамки невоенных методов осуществления политики «освобождения». По решению СНБ США, одобренному президентом в марте 1954 г., ЦРУ предписывалось «в районах, управляемых, или находящихся под угрозой управления международного коммунизма, организовывать подпольное сопротивление, способствовать скрытым партизанским операциям и обеспечить наличие этих сил сопротивления на случай войны и снабжение баз, с которых они могли бы осуществлять свою деятельность» [21, p. 190]. В Венгрии, например, при участии американской разведки был создан ряд тайных организаций, часть которых носила военный характер: «Белые партизаны», «Движение национального сопротивления», «Объединение юнкеров» и другие, большинство из которых были раскрыты венгерскими органами госбезопасности [22, с. 468].

В середине 1950-х гг. в странах Восточной Европы обостряется социально-экономическая обстановка. Условия «холодной войны» диктовали ускоренные темпы развития отдельных отраслей экономики, особенно тяжелой промышленности. Форсированные индустриализация и коллективизация привели уже в начале 1950-х гг. к резким диспропорциям в развитии экономики ряда стран народной демократии. В июне 1956 г. начались народные волнения в Польше, где усилилось движение за политические и экономические реформы. Вероятность возникновения народных волнений существовала и в Венгрии, где ситуация также грозила вылиться в социальнополитический кризис. Во избежание этого венгерским руководством при консультации с Москвой было решено сместить М. Ракоши, чья политика вызывала резкое неприятие венгерского общества, с поста первого секретаря Центрального руководства Венгерской партии труда (ЦР ВПТ). 19 июля 1956 г. главой венгерской компартии был назначен Э. Гере.

Учитывая перемены в странах народной демократии, США начали корректировать свою тактику в отношении государств Восточной Европы. Так, например, СНБ США в июле 1956 г. был одобрен новый подход к государствам-союзникам Советского Союза по Организации Варшавского Договора (ОВД), согласно которому для постепенного ослабления связей восточноевропейских стран с Советским Союзом признавалось уместным моделирование отношений этих стран с Москвой по принципу взаимоотношения Югославии и СССР. Югославская модель более самостоятельной от Кремля внешней политики, будучи принятой остальными странами Центральной и Восточной Европы, по мнению американского руководства, больше соответствовала бы интересам США [23, p. 190-194, 216-221]. Некоторое изменение тактики действий Вашингтона было вызвано также и пониманием того, что, как докладывали аналитики ЦРУ летом 1956 г., несмотря на все усилия американской разведки, в Венгрии так и не удалось создать постоянные подпольные группы, которые могли бы оказывать длительное и эффективное сопротивление Советской армии в случае начала вооруженного мятежа [24, p. 340, 365].

В Венгрии обострение социального конфликта было во многом связано с вопросом о смене руководства в венгерском правительстве и ВПТ. Э. Гере 
и его окружению не удалось стабилизировать ситуацию в стране. 22-23 октября 1956 г. на улицы Будапешта вышли студенты и рабочие с призывами следовать польскому примеру и добиваться восстановления на государственных и партийных постах И. Надя, возглавлявшего в 1953-1955 гг. венгерское правительство и выступавшего с программой экономических и политических реформ. Среди лозунгов манифестантов были требования строить внешнюю политику ВПТ на основе полного равноправия и суверенитета, политической и экономической самостоятельности. Прибывшие из Москвы для консультации венгерского руководства А.И. Микоян и М.А. Суслов участвовали в экстренном заседании ЦР ВПТ, состоявшемся в ночь с 23 на 24 октября, на котором было принято решение избрать И. Надя главой правительства. Одновременно с этим в Будапешт были введены советские войска, начались столкновения с демонстрантами.

Возможность американского военного вмешательства в венгерские события, принимая во внимание существовавший раздел сфер влияния в Европе, отвергалась Д. Эйзенхауэром и Дж.Ф. Даллесом с самого начала. В своих публичных выступлениях президент США объяснял это географическим положением Венгрии, окруженной странами народной демократии и нейтральной Австрией. В действительности Соединенные Штаты не желали идти на риск глобального конфликта с Советским Союзом даже из-за вероятного шанса вывести Венгрию из орбиты советского влияния. Несмотря на лозунги «отбрасывания коммунизма» и доктрину «освобождения», Соединенные Штаты учитывали наличие Организации Варшавского Договора, участнику которого, ставшему жертвой внешней агрессии, гарантировалась военная помощь от других членов пакта.

С начала вооруженного восстания в Венгрии американская дипломатия преследовала две цели: с одной стороны, убедить мировое общественное мнение в том, что Соединенные Штаты не собираются оставаться в стороне от событий в Будапеште, а с другой, - не обостряя отношений с СССР, использовать в пропагандистских целях действия Советского Союза в этой восточноевропейской стране. 26 октября на заседании СНБ помощник президента США по вопросам разоружения Г. Стассен предложил попытаться прозондировать мнение советского руководства о возможности создания в Центральной и Восточной Европе континуума нейтральных стран, района, в котором не были бы размещены войска того или иного блока, допуская даже их политическую (но не военную) ориентацию на СССР, по примеру Австрии, которая традиционно более близка к Западу, но, тем не менее, не является членом НАТО. Для этого Стассен предлагал использовать различные дипломатические каналы, например, действовать через югославского лидера Йосипа Броз Тито.

В конечном итоге, Эйзенхауэр поручил Даллесу в каком-либо виде уверить советское руководство в приверженности Соединенных Штатов послевоенному статус-кво в Европе. Государственный секретарь США сделал это на следующий день, выступая в Далласе, где он заявил, что Соединенные Штаты не рассматривают страны-сателлиты СССР в качестве своих «потенциальных военных союзников» [25]. Через несколько дней в Организации Объединенных Наций это же повторил представитель США Генри Кэбот Лодж, а затем и сам Эйзенхауэр во время телевизионного обращения к американскому народу 31 октября [26, p. 1061-1062].

На следующий день после ввода советских войск в Будапешт Дж.Ф. Даллес обсудил со своими помощниками проблему передачи вопроса о ситуации в Венгрии в Организацию Объединенных Наций. Посол США в Москве Ч. Болен советовал повременить с передачей венгерского вопроса в $\mathrm{OOH}$, до тех пор, пока не станет ясна позиция советского руководства и нового венгерского правительства. Преждевременное обсуждение этой проблемы, по мнению американского посла, только стеснило бы действия И. Надя, если бы Кремль дал согласие на проведение политических преобразований в Венгрии [27, p. 136]. Тем не менее американское руководство решило в целях сохранения своего международного престижа и активизации внимания мировой общественности к венгерскому мятежу поставить вопрос о событиях в Будапеште на повестке дня заседания Совета Безопасности ООН. Одновременно Г.К. Лоджу было указано не форсировать принятие резолюции по данному вопросу, обсуждение которого началось 28 октября, делая все, чтобы предотвратить голосование или передачу его на рассмотрение Генеральной Ассамблее $\mathrm{OOH}$ до тех пор, пока окончательно не прояснится ситуация в Венгрии и позиции сторон [23, р. 273].

Участники антисоветских выступлений в Венгрии рассчитывали на американскую помощь. Согласно опросу венгерских беженцев в Австрии, проведенному после подавления венгерского восстания, большинство из них (96\%) ожидали поддержки со стороны США и 77\% из них считали, что эта поддержка будет военного характера [1]. Помощь же Соединенных Штатов мятежникам в Венгрии свелась к действиям в рамках $\mathrm{OOH}$ и активизации работы радиостанций, вещающих на территорию Восточной Европы. С 24 октября радиостанция «Свободная Европа» перешла от шестичасового ежесуточного вещания к двадцатичасовому. Несмотря на то, что к Эйзенхауэру неоднократно обращались специалисты ЦРУ с просьбой разрешить сбросить 
венграм оружие и продовольствие с воздуха, они неизменно получали отказ президента США. Не рассматривал глава Белого дома всерьез и возможность отправки американских войск в Венгрию, которая представлялась ему «такой же недоступной для американцев, как и Тибет» [28, p. 89, 95].

Определенный оптимизм у администрации президента вызывали сообщения из Будапешта, где И. Надь с согласия Микояна и Суслова заявил о ликвидации однопартийной системы и выводе советских войск с территории Венгрии. Свидетельства некоторых американских авторов о том, что московские эмиссары дали согласие начать переговоры по выходу Венгрии из Организации Варшавского договора, как показывают материалы советских архивов, переданных Россией венгерской стороне в начале 1990-х гг., не являются достоверными [29, р. 238; 30 , с. $73-104 ; 31]$.

31 октября 1956 г. советское руководство изменило свою позицию. После многочасовых дискуссий в рамках заседания Президиума ЦК КПСС было решено приступить ко второму этапу военной операции в Венгрии, получившей кодовое название «Вихрь». Целью операции было смещение правительства И. Надя, не справившегося, по мнению советского руководства, с возложенной на него задачей стабилизации обстановки в Венгрии и проводящего политику, угрожающую единству социалистического лагеря. На этот шаг, в некотором отношении, повлияло начало англо-франко-израильской агрессии против Египта и неожиданно резкое изменение позиции Китайской Народной Республики, первоначально выступавшей против возвращения советских войск в Будапешт, вывод которых осуществлялся 29-30 октября. Н.С. Хрущев, кроме того, опасался ослабления своих позиций среди руководства вооруженных сил СССР и внутри Политбюро в результате возможной критики его политики, результатом которой, как считали некоторые члены советского правительства, возникла угроза «потери Венгрии».

В госдепартаменте США одновременно с активизацией внимания общественности к венгерским событиям изучались различные варианты развития событий в Восточной Европе и возможные действия Вашингтона, связанные с ними. Несмотря на демонстрацию готовности советского руководства к политическому диалогу с венгерской стороной, американские дипломаты наиболее вероятным вариантом действий Кремля по-прежнему считали силовое подавление мятежа и полагали необходимым в случае, когда это произойдет, использовать этот исход событий в своих интересах, в частности на Ближнем и Среднем Востоке. Дж.Ф. Даллес в своей директиве американским дипломатическим миссиям в связи с положением в Венгрии обращал внимание на следующее: «Вопрос в том, позволят ли Советы осуществить стабилизацию под руководством того Надя, который стал приверженцем вывода их войск, со всеми вытекающими отсюда последствиями для остальных стран-сателлитов, или же в качестве иностранных оккупантов вновь восстановят полный контроль над страной, что на будущее чревато тяжелыми военными расходами и подрывом их сегодняшних позиций на международной арене» [32, с. 273]. В Вашингтоне полагали, что венгерские события можно было бы использовать для демонстрации Египту и Сирии последствий, которые может принести расширение экономического и политического сотрудничества с Советским Союзом.

Осуществлению этих замыслов американской дипломатии помешало начало тройственной агрессии против Египта. Д. Эйзенхауэр вынужден был перенести все внимание Совета Национальной Безопасности, созванного 1 ноября для обсуждения ситуации в Венгрии, на боевые действия на Ближнем Востоке. В целях предупреждения критики, которая могла возникнуть в адрес американского внешнеполитического ведомства в результате возникновения ближневосточного кризиса, Дж.Ф. Даллес счел необходимым связать агрессию на Ближнем Востоке с событиями в Венгрии. На упомянутом заседании СНБ Дж.Ф. Даллес отметил, что «в то время, когда мы близки к неминуемой и давно ожидаемой победе над советским колониализмом в Восточной Европе, мы вынуждены выбирать: идти ли нам вслед за англо-французским колониализмом в Азии и Африке, или проводить свою собственную, отличную от них политику» [33, р. 907].

Тем самым государственный секретарь попытался возложить всю ответственность за возникновение Суэцкого кризиса на союзников США по НАТО. Свое недовольство действиями Лондона и Парижа на Ближнем Востоке в тот момент, когда Советский Союз испытывал значительные трудности в Восточной Европе, госсекретарь США подчеркнул также и в разговоре с послом Франции в Вашингтоне Э. Альфаном [33, p. 868].

Английская и французская делегации в $\mathrm{OOH}$, чтобы отвлечь внимание от тройственной агрессии, стремились поставить вопрос о ситуации в Венгрии на рассмотрение Генеральной Ассамблеей ОOH. Против этого выступали Соединенные Штаты, ожидавшие того, что последует за начавшимся в конце октября выводом советских войск из Будапешта. По указанию президента США Генри К. Лодж на время вообще прервал консультации с представителями Лондона и Парижа по ситуации в Венгрии. И только 3 ноября, после донесений американской разведки о концентрации советских войск вокруг Будапешта, Лодж представил на рассмотрение Совета Безопасности резолюцию, призывающую Советский Союз «воздерживаться от вмешатель- 
ства в какой-либо форме, особенно вооруженного вмешательства, во внутренние дела Венгрии». После того, как на эту резолюцию советский представитель в $\mathrm{OOH} \mathrm{А.А.} \mathrm{Соболев} \mathrm{наложил} \mathrm{вето,} \mathrm{по} \mathrm{предложе-}$ нию делегации США вопрос о ситуации в Венгрии был передан на рассмотрение чрезвычайной сессии Генеральной Ассамблеи ООН, созванной в связи с событиями в Египте.

Вновь американская дипломатия действовала в одностороннем порядке, не консультируясь со своими британскими и французскими коллегами. Британский представитель в ООН П. Диксон назвал такое поведение «образцом американской двуличности» [34]. 4 ноября была принята резолюция Генеральной Ассамблеи, призывающая СССР «немедленно прекратить вооруженное нападение... не направлять больше войсковых соединений в Венгрию, а уже направленные - вывести» и утверждающая «право венгерского народа в свободном выборе правительства и формы жизни» [35; 36].

В этот же день Генеральная Ассамблея ООН приняла также решение о создании международного миротворческого контингента для разъединения враждующих сторон на египетской территории. Очевидно, что на внесение для обсуждения Генеральной Ассамблеей $\mathrm{OOH}$ проекта резолюции о создании Чрезвычайных вооруженных сил (ЧВС) $\mathrm{OOH} \mathrm{повлияло} \mathrm{в} \mathrm{определенной} \mathrm{мере} \mathrm{и} \mathrm{развитие}$ ситуации в Венгрии. В этот день Советский Союз приступил к выполнению операции «Вихрь», введя в Будапешт усиленный контингент своих войск. Эксперты госдепартамента и ЦРУ прогнозировали активизацию ближневосточной политики СССР сразу же после подавления венгерского мятежа. Решение Чрезвычайной специальной сессии Генеральной Ассамблеи $\mathrm{OOH}$ о создании Чрезвычайных вооруженных сил Организации Объединенных Наций, по замыслу госдепартамента США, должно было существенно ограничить возможности советской дипломатии по вмешательству в Суэцкий кризис. По замечанию Д. Эйзенхауэра, сделанному на совещании со своими помощниками 4 ноября 1956 г., если бы Великобритания и Франция прекратили вооруженные действия на Ближнем Востоке, у Соединенных Штатов появилась бы возможность перенести все внимание мировой общественности на события в Венгрии [33, р. 976-977]. Необходимость попытаться лишить Москву возможности перевести внимание мировой общественности от действий Советского Союза в Венгрии на события вокруг Египта отчасти явилась причиной нажима, оказанного Вашингтоном в отношении своих союзников по Североатлантическому договору в целях прекращении агрессии против Египта.

Правительство Д. Эйзенхауэра применило экономическое и дипломатическое давление на участ- ников агрессии в целях ее скорейшего завершения. В частности, Лондону было отказано в оказании финансовой помощи, в которой отчаянно нуждалась британская экономика. Были приостановлены также поставки американской нефти в Соединенное Королевство и существенно ограничены контакты на официальном уровне между американскими и британскими политиками [37, с. 100]. Помимо внутриполитических соображений, американская администрация руководствовалась стремлением не допустить усиления влияния Советского Союза, также выступившего с жесткими требованиями прекращения военных действий на египетской территории.

Очевидно, что в контексте глобальной политики США американское руководство придавало наибольшее значение процессам, происходящим в Центральной и Восточной Европе. В послевоенной региональной внешней политике США Европа, безусловно, занимала приоритетное место. В этом плане для Соединенных Штатов было важнее акцентировать внимание Генеральной Ассамблеи ООН на способе решения Москвой тех трудностей, с которыми пришлось столкнуться Советскому Союзу в странах Организации Варшавского Договора.

Вместе с тем руководство Соединенных Штатов не отказывалось от своего намерения использовать вопрос о венгерских событиях в интересах своей ближневосточной политики. Позиция арабских стран в Организации Объединенных Наций демонстрировала, что в этом отношении перед американской дипломатией могут возникнуть определенные сложности. Во время голосования на Генеральной Ассамблее ООН по резолюции о ситуации в Венгрии представители всех арабских государств предпочли воздержаться. Для того, чтобы противодействовать распространению влияния СССР в развивающихся странах, Соединенные Штаты должны были, как об этом заявил Д. Эйзенхауэр на заседании Совета Национальной Безопасности 8 ноября, помимо других мер, в том числе и максимально усилить пропаганду тезиса о якобы объективно присущей внешней политике Советского Союза агрессивности. Свидетельства о действиях советской армии в Венгрии, включая доступные документы, фотографии и кинопленки, снятые на улицах Будапешта, по мнению президента США, следовало бы сделать достоянием гласности с тем, чтобы дать понять лидерам развивающихся стран, особенно на Ближнем Востоке, какие последствия может принести им ориентация на СССР [33, p. 1081, 1083].

События в Венгрии были использованы также американским руководством для того, чтобы предотвратить предполагаемую критику действий США во время Суэцкого кризиса со стороны их основных стратегических партнеров по НАТО. 9 ноября Д. Эйзенхауэр в разговоре с новым британским 
послом в Вашингтоне Г. Кассиа заметил, что негативное отношение Соединенных Штатов к тройственной агрессии и поведение американской делегации в ООН определялось прежде всего тем, что Лондон и Париж выбрали для начала военной операции на Ближнем Востоке неподходящее с точки зрения Вашингтона время. Президент США подкрепил свое высказывание цитатой из письма некоего члена правительства И. Надя, в котором утверждалось, что лишь нападение Англии и Франции на Египет позволило Советскому Союзу без особой критики со стороны мирового сообщества подавить венгерский мятеж [33, p. 1098].

Тройственная агрессия против Египта и венгерский мятеж завершились приблизительно одновременно: 6 ноября Англия и Франция заявили о прекращении боевых действий на Ближнем Востоке, к этому же дню советские войска подавили все основные очаги сопротивления венгерских повстанцев. Политика Соединенных Штатов во время Суэцкого кризиса привела укреплению позиций США на Ближнем и Среднем Востоке, но одновременно, в связи с тройственной агрессией против Египта, было отмечено также падение авторитета стран НАТО и рост влияния Советского Союза в арабских государствах.

Хронологическое совпадение двух международных кризисов, на Ближнем Востоке и в Восточной Европе, нередко вызывало желание у отечественных и зарубежных авторов выявить взаимосвязь этих двух событий, подчеркнуть, что появление одного из кризисов не было бы возможным без наличия другого. Однако, несмотря на то, что и при согласовании Англией, Францией и Израилем решения о совместной акции против Египта на совещании представителей этих стран 22-24 октября в предместье Парижа Севре, и при принятии Советским Союзом решения о начале второго этапа подавления венгерского мятежа (операция «Вихрь»), неизменно учитывался фактор международной обстановки, оба кризиса развивались самостоятельно.

Нападение на Египет планировалось еще до начала венгерского мятежа, и занятость Советского Союза проблемами внутри своего блока рассматривалась участниками нападения как неожиданное подспорье для планируемой агрессии, снижающее возможности Москвы по вмешательству в Суэцкий кризис. Также и Н.С. Хрущев, по свидетельству югославского посла в Москве В. Мичуновича, объяснял на встрече с Й. Броз Тито 2-3 ноября на острове Бриони в Югославии, что одной из причин (выделено мной. - B. Р.) необходимости начала операции «Вихрь» являлась тройственная агрессия против Египта, которая в некоторой степени отвлекла внимание мировой общественности от подавления «контрреволюции» в Венгрии [29, р. 242]. Влияние Суэцкого кризиса на решение советского руководства вернуть выведенные из Будапешта войска прослеживается, таким образом, в основном в отношении даты начала операции «Вихрь».

Что же касается Соединенных Штатов, то драматические события в Венгрии, что бы потом ни говорили американские лидеры, сыграли пусть и важную, но не первостепенную роль в давлении Вашингтона на участников тройственной агрессии. Гораздо важнее были соображения, связанные с переизбранием Д. Эйзенхауэра на второй президентский срок.

События 1956 г. на Ближнем Востоке и в Восточной Европе выявили стремление Вашингтона и Москвы придерживаться установленных сфер влияния, что не исключало, впрочем, готовности двух сверхдержав попытаться изменить это положение в будущем. Возникновение венгерского мятежа активно использовалось американским руководством для оправдания просчетов своей дипломатии на Ближнем Востоке и привлечения развивающихся стран к сотрудничеству с Соединенными Штатами. В то же время безусловный успех советской дипломатии во время Суэцкого кризиса был воспринят в Москве как возможность усилить свои политические, экономические и стратегические позиции в различных регионах мира, что привело в итоге к возникновению Карибского кризиса 1962 г.

\section{Библиографический список}

1. Bekes C. The 1956 Hungarian Revolution and World Politics. URL: https://www.wilsoncenter.org/sites/default/ files/ACFB4E.pdf (дата посещения: 18.07.2019).

2. Borhi L. Dealing with Dictators: the United States, Hungary, and East Central Europe, 1942-1989. Bloomington, 2016.

3. Molnár M. Budapest 1956: A History of the Hungarian Revolution. L., 1971.
4. Radványi J. Hungary and the Superpowers: The 1956 Revolution and Realpolitik. Stanford, CA, 1972.

5. Hungary, 1956: Forty Years On / Ed. by T. Cox. L., 1998.

6. The Hungarian Revolution of 1956: Reform, Revolt and Repression / Ed. by G. Litvan. N.Y., 1996.

7. Gati C. Hungary and the Soviet Union. Durham, 1986.

8. The Hungarian Revolution of 1956 and its Impact / Ed. by B.K. Kuraly. N.Y., 1984. 
9. Советский Союз и венгерский кризис 1956 года. Документы. М., 1998

10. Granville J. Hungary, 1956: The Yugoslav Connection // Europe-Asia Studies. 1998. Vol. 50. №3. DOI: 10.1080/09668139808412549.

11. Granville J. Of Spies, Refugees and Hostile Propaganda: How Austria Dealt with the Hungarian Crisis of 1956 // History. 2006. Vol. 91. №1. DOI: 10.1111/j.1468229X.2006.00359.x.

12. Granville J. Ulbricht in October 1956: Survival of the Spitzbart during Destalinization // Journal of Contemporary History. 2006. Vol. 41. №3. DOI: 10.1177/ 0022009406064656.

13. Granville J. The Last of the Mohicans: How Walter Ulbricht Endured the Hungarian Crisis of 1956 // German Politics \& Society. 2004. Vol. 22. №4. DOI: 10.3167/ gps.2004.220403.

14. Zonova T. 1956: Moscow - Budapest in the Context of Cold and Hot Wars // Rivista Di Studi Politici Internazionali. 2007. Vol. 74. №2.

15. McCauley B. Hungary and Suez, 1956: The Limits of Soviet and American Power Source // Journal of Contemporary History. 1981. Vol. 16. №4. DOI: 10.1177/ 002200948101600408.

16. Boyle P.The Hungarian Revolution and the Suez Crisis // History. 2005. Vol. 90. №4. DOI: 10.1111/j.1468229X.2005.00350.x.

17. Румянцев В.П. Д. Эйзенхауэр и решение об отправке американских войск в Ливан в 1958 г. // Вестник Томского государственного университета. 2007. № 305.

18. Life. 1952. May 19.

19. Foreign Relations of the United States (FRUS).19521954. Vol. II. National Security Affairs (in two parts). Pt. 1. Wash.,1984.

20. Granville J. "Caught with Jam on Our Fingers": Radio Free Europe and the Hungarian Revolution of 1956 // Diplomatic History. 2005. Vol. 29. №5. DOI: 10.1111/j.14677709.2005.00519.x.

21. Gaddis J. The Long Peace: Inquiries into the History of the Cold War. N.Y. ; Oxford, 1987.
22. Краткая история Венгрии. С древнейших времен до наших дней. М., 1991.

23. FRUS. 1955-1957. Vol. XXV. Eastern Europe. Wash.,1990.

24. Calhoun D. Hungary and Suez, 1956: An Exploration of Who Makes History. Lanham MD, 1991.

25. The Department of States Bulletin. 1956. November 5.

26. Public Papers of the Presidents of the United States, Dwight D. Eisenhower. Containing the Public Messages, Speeches and Statements of the President. 1956. January 1 to December 31, 1956. Wash., 1958.

27. Ruddy M. The Cautious Diplomat: Charles E. Bohlen and the Soviet Union, 1929-1969. Kent and L., 1986.

28. Eisenhower D.D. The White House Years: Waging Peace, 1956-1961. N.Y., 1965.

29. Campbell J. The Soviet Union, the United States, and the Twin Crises of Hungary and Suez // Suez 1956. The Crisis and Its Consequences / Ed. by Wm. Louis and R. Owen. Oxford, 1989.

30. Середа В. Т. Как решались вопросы «Венгрии». Рабочие записи заседаний Президиума ЦК КПСС. Июльноябрь 1956 г. // Исторический архив. 1996. №2.

31. Rainer J. The Yeltsin Dossier: Soviet Documents on Hungary, 1956. URL: https://www.wilsoncenter.org/sites/ default/files/CWIHPBulletin5_p1.pdf (дата посещения: 18.07.2019).

32. Желицки Б.Й. Будапешт - Москва: год 1956 // Советская внешняя политика в годы «холодной войны» (1945-1985). Новое прочтение / отв. ред. Л.Н. Нежинский. М., 1995.

33. FRUS. 1955-1957. Vol. XVI. The Suez Crisis. July 26December 31, 1956. Wash.,1990.

34. The National Archives of the United Kingdom. FO 371/122381. New York to Foreign Office, 4 November 1956. 35. The Department of States Bulletin. 1956. November 12. 36. The Department of States Bulletin. 1956. November 19.

37. Румянцев В.П. Англо-американские переговоры по вопросам политики на Ближнем и Среднем Востоке (март-апрель 1957 г.) // Вестник Томского государственного университета. 2010. №331. 